\title{
Evolução da coluna social ao longo do século $\mathbf{X X}^{\mathbf{1}}$
}

Beatriz DORNELLES ${ }^{2}$

\begin{abstract}
Resumo:
Este trabalho parte de uma pesquisa historiográfica e documental sobre a produção da coluna social ao longo do século XX, desde sua origem, nos Estados Unidos, suas marcas históricas no Brasil e sua introdução no interior do Rio Grande do Sul, objetivando apresentar as mudanças ocorridas ao longo do período. Apresentamos as principais características e identificamos diferentes fases, efetuando uma periodização a partir das mudanças ocorridas. Apresentamos a divisão, de forma não linear, em quatro etapas: de 1920 a 1940; de 1940 a 1950; de 1960 a 1980; de 1990 ao século XXI. Realizamos a análise documental e bibliográfica considerando linguagem, fontes, temática e modificações que sofreu na sua forma de produção. Concluiu-se que os colunistas gaúchos foram influenciados por colunistas da grande imprensa dos anos 40, 50 e 60, mantendo o mesmo modelo até o final do século XX.
\end{abstract}

Palavras-chave:

Coluna social. Produção da notícia. Colunista social.

\section{Evolution of the social columns throughout the 20th Century}

\begin{abstract}
:
This work departs from historical and document research on the production of social columns throughout the 20th Century, since their origins in the United States, their historical marks in Brazil and their introduction in the countryside of Rio Grande do Sul, with the objective to present the changes occurred along the period. We present the main characteristics and identify different phases, divided in a non-linear form, according to the period the changes have occurred: from 1920 to 1940; from 1940 to 1950; from 1960 to 1980; from 1990 to the 21st Century. The analysis considers language, sources, themes and modifications in the forms of production. We conclude that Brazilian social columnists from Rio Grande do Sul have been influenced by those of the major press of the 1940s, 1950s and 1960s, maintaining the same model up until the end of the 20th Century.
\end{abstract}

Keywords:

Social column. Production of news. Social columnist.

\section{Evolución de la columna social a lo largo del siglo XX}

\begin{abstract}
Resumen:
Este trabajo surge de una investigación historiográfica y documental sobre la producción de la columna social a lo largo del siglo XX, desde su origen, en Estados Unidos, sus marcas históricas en Brasil y su introducción en el interior de Río Grande do Sul, con el objetivo de presentar los cambios ocurridos a lo largo del período. Presentamos las principales características e identificamos diferentes fases, efectuando una periodización a partir de los cambios ocurridos. Presentamos la división, de forma no linear, en cuatro etapas: de 1920 a 1940; de 1940 a 1950; de 1960 a 1980; de 1990 al siglo XXI. Realizamos el análisis documental y bibliográfico considerando lenguaje, fuentes, temática y modificaciones que sufrió en su forma de producción. Se concluyó que los columnistas gauchos fueron influenciados por columnistas de la gran prensa de los años 40,50 y 60, manteniendo el mismo modelo hasta el final del siglo XX.

Palabras clave:

Columna social. Producción de la noticia. Columnista social.

1 Trabalho apresentado no GT de História do Jornalismo, integrante do $10^{\circ}$ Encontro Nacional de História da Mídia, 2015.

${ }^{2}$ Doutora em Comunicação pela Universidade de São Paulo (1999) e pós-doutora em Comunicação pela Universidade Fernando Pessoa-Portugal (2009). Professora titular do Programa de Pós-Graduação em Comunicação Social da PUC-RS e editora executiva da Revista Famecos. Atua em linha de pesquisa com ênfase em jornalismo do interior e sua transição para o jornalismo digital.E-mail: biacpd@pucrs.br
\end{abstract}




\section{INTRODUÇÃO}

Dentre os gêneros textuais do jornalismo opinativo, a coluna popularizou-se entre jornalistas e escritores do noticiário brasileiro, servindo, inclusive, para consagrar nomes de profissionais que inovaram e criaram marcas pessoais, utilizando-se desse expediente. Dentre os vários tipos de colunas que se firmaram ao redor do mundo, está a coluna social, utilizada para representar a trajetória de vida de elites da sociedade, o que elas fazem de suas vidas e como o fazem, que valores permeiam suas mentes e como interagem entre si e com as demais camadas sociais de menor poder aquisitivo (GONÇALVES, 1999).

Outra contribuição da coluna social para o Jornalismo é permitir compreender o papel do colunista e suas relações com a elite, estabelecendo, assim, um parâmetro de comportamento para a cobertura jornalística desse setor pelos profissionais que ingressam na área ou que desejam atuar como colunistas sociais. Corrobora para essa afirmação a trajetória profissional do notório jornalista Ibrahim Sued (SUED, 2001), que, ao longo de 45 anos (1950-1995), trabalhou como colunista social na imprensa carioca, servindo de referência a diversos colunistas que integram a imprensa interiorana no Brasil, o que aconteceu no Rio Grande do Sul, conforme pudemos constatar na pesquisa realizada para este e outros estudos anteriores.

Para entendermos as nuances que se apresentaram nas colunas sociais gaúchas ao longo do século XX, buscamos compará-las com os marcos históricos do gênero no Brasil e no mundo. Por isso, a necessidade de apresentar importantes contribuições de colunistas notórios no período estudado.

É o caso, por exemplo, de Ibraim Sued. Sua primeira coluna começou a circular em 1951 e apresentou um estilo pessoal, aberto, espontâneo e agressivo. Suas notas não retrataram apenas as "fofocas e a vida mundana das elites" 3 , mas difundiram notícias de política, economia, comportamento, moda, artes, internacional e cultura em geral, o que deu uma amplitude à área de ação dos colunistas sociais. Por muito tempo, Ibrahim representou o colunismo social no Rio de Janeiro e foi referência nacional para jornalistas e colunistas sociais que se espalharam pelos jornais do país, tendo ampla aceitabilidade em muitas cidades do interior do Brasil.

Acreditando no valor cultural, social e histórico do noticiário desse gênero para a história do jornalismo brasileiro, em um primeiro momento, efetuamos uma análise

\footnotetext{
${ }^{3}$ Grifo nosso.
} 
historiográfica e documental, visando identificar as principais características da coluna social ao longo do século XX (desde o seu surgimento), em uma periodização por décadas.

Para fins de registro histórico, observamos o modelo de coluna social desde sua origem, nos Estados Unidos, como se desenvolveu no Brasil e como foi introduzida na imprensa gaúcha do interior. Apresentamos uma descrição analítica de colunas sociais estudadas por pesquisadores da área de comunicação de maneira sucinta (por restrição de espaço) $)^{4}$.

\section{Antecessores da coluna social}

Brito Broca, em A vida literária no Brasil 1900 (2004), delimita o ano de 1907 como o do surgimento da primeira coluna social na imprensa brasileira, denominada Binóculo, escrita pelo jornalista Figueiredo Pimentel. A partir dali surgiu um processo generalizado de tornar menos pesados os textos dos jornais. No início do século 20, o noticiário social era visto como o lado informal do jornal, voltado para o público feminino. Uma espécie de contraponto às notícias sobre crimes, violência e mortes do jornalismo sensacionalista, praticado na época no país (KOVÁCS, 1979).

Dentro desse contexto, as notas publicadas nas colunas eram feitas com humor. As notícias abordando os integrantes da burguesia eram escritas, algumas vezes, de forma irônica, ressaltando o lado extravagante dos ricos, e, aos poucos, dando maior importância às fofocas, ainda sem atingir seriamente a reputação dos personagens retratados (RAMALHO, 1998). Com o tempo as colunas sociais foram sofrendo alterações, inaugurando um estilo também chamado gossip column - ou coluna de mexericos, como foi chamada no Brasil.

\section{Origem da coluna social: de 1920 a 1940}

\footnotetext{
${ }^{4}$ Não estabelecemos entre nossos objetivos tratar de todos os colunistas que fizeram história no Brasil, servindo de modelo a quase todos os colunistas de cidades do interior. Se assim o fosse, não poderíamos deixar de citar o influente trabalho de Zózimo, que deixou um conjunto com mais de 170 mil notas, publicadas ao longo de 28 anos de trabalho na imprensa carioca. Zózimo começou a carreira em 1966, quando assumiu em $O$ Globo a coluna Carlos Swann, que fora escrita antes por Ibrahim Sued (BRASIL, 2006). Também é de grande valor para a história do colunismo social o trabalho de Ancelmo Góis, n'O Globo, e Boechat, no Jornal do Brasil (JB). De igual importância é a obra de Paulo Raymundo Gasparotto, que exerceu o colunismo nos principais diários de Porto Alegre a partir de 1961.
} 
No formato que se apresentou durante quase todo o século XX e início do XXI na imprensa brasileira, a origem da coluna social tem uma história que começa na década de 20, do século XX, nos Estados Unidos. Teve várias reformulações e momentos jornalísticos, sempre relacionados aos acontecimentos sociopolíticos, econômicos, culturais e tecnológicos que marcaram a sociedade naquele período.

A coluna social contribuiu e inovou para a evolução dos critérios de noticiabilidade tradicionais. Em nossa pesquisa, a leitura analítica da bibliografia mostrou mudanças ocorridas em sua produção ao longo do século $\mathrm{XX}$, revelando como ela acompanhou a evolução do jornalismo nesse período.

A coluna social foi criada pelo jornalista norte-americano Walter Winchell, nascido em Nova York, em 1897, filho de imigrantes judeus. Seu primeiro trabalho, antes de se profissionalizar, consistia em escrever fofocas dos bastidores das peças teatrais nas quais atuava, que eram divulgadas pelos boletins informativos da área teatral (TRAVANCAS, 2000). Na década de 1920, após tornar-se jornalista profissional, Winchell pôs em prática seu sonho: uma coluna de fofocas sobre os ricos e famosos da época. Nasciam ali as gossip columns (colunas de fofocas).

Até aquele momento, as notícias sociais publicadas nos Estados Unidos eram muito próximas àquelas intituladas, no Brasil, como "Sociais", ou seja, relatos respeitosos sobre personagens da alta sociedade, avisos de casamentos, nascimentos, formaturas, recepções, festas, noivados, bailes de 15 anos etc. (FERREIRA, 2006). Naquela época, alguns tipos de "colunas de fofocas" já existiam no Brasil ${ }^{5}$, "mas sempre num tom bajulador quanto às pessoas retratadas" (SOUZA, 2007, p. 6).

A coluna sobre sociedade foi inovada por Winchell. Ele criou as pequenas notas sobre a vida privada, acrescentando aqui e ali um ponto de vista "debochado e sarcástico" ${ }^{6}$ sobre pessoas famosas (GONÇALVES, 1999). Como reflexo do estilo jornalístico da época, o colunista divulgava escândalos típicos da imprensa sensacionalista, como informações não oficiais sobre mulheres grávidas, divórcios e especulações.

Winchell foi o primeiro jornalista a romper o tabu existente até então, que rejeitava a exposição da vida privada de pessoas públicas, o que alterou

\footnotetext{
5 As colunas sociais não tinham o formato que conhecemos hoje. A maioria delas estava exposta em uma página sob a denominação "Sociais" e o colunista não era conhecido do grande público, até porque as tiragens dos jornais eram baixas.

${ }^{6}$ Grifo nosso.
} 
permanentemente as relações entre "jornalismo e celebridades" 7. Seu estilo foi impactante quando começou a escrever para o jornal New York Evening Graphic, em 1920. Os editores dos jornais concorrentes viram o que ele fizera pela circulação do periódico e rapidamente providenciaram suas próprias gossip columns.

A fórmula criada pelo colunista norte-americano foi utilizada com sucesso em Hollywood. Nas décadas de 1930 e 1940, conhecidas como a "era de ouro" dos estúdios, produtores cinematográficos seduziram colunistas sociais com a intenção de garantir maior publicidade para seus filmes e elencos.

As colunas eram parte integrante dos jornais, e os colunistas sociais eram amados e respeitados pelo público norte-americano. No mesmo período, no Brasil, a coluna social ainda não havia evoluído. Continuavam aparecendo notas sobre eventos e autoridades, sem a existência de um colunista social.

Muito antes da expressão "celebridade" se tornar corrente na grande imprensa, o jornalista Walter Winchell era, ele próprio, uma celebridade, considerado por toda a imprensa como um dos homens mais poderosos da América. Ninguém queria ter problemas com aquele homem que criara as famosas gossip columns (SOUZA, 2007), um gênero que depois faria o sucesso de centenas de publicações sobre o cotidiano de poderosos, ricos e famosos.

As notícias em tom de fofoca sobre famosos já eram comuns na Europa, mas o estilo em notas curtas, sincopadas (em que uma nota pode completar o que foi sugerido pela anterior) é uma invenção americana. Os primeiros colunistas que surgiram trabalhavam relatando notas sobre artistas, milionários, figuras excêntricas, autoridades e outras pessoas da sociedade que pudessem ser destaque na coluna. A leveza da linguagem utilizada nas notas sociais obteve grande sucesso e inspirou o colunismo social ao redor do mundo, inclusive no Brasil.

\section{Segundo período: de 1940 a 1950}

Na década de 1940, a Segunda Guerra Mundial provocou uma mudança na recepção das antigas colunas sociais. A sociedade americana tinha uma nova obsessão: todos queriam ler notícias sobre escândalos. Aos poucos, elas foram se proliferando nas colunas de notas, primeiro como escândalos privados, adultérios, crimes passionais de pessoas famosas, enquanto assuntos como política e economia eram inseridos disfarçadamente no corpo das colunas (SOUZA, 2009).

\footnotetext{
${ }^{7}$ Grifo nosso.
} 
No Brasil, no mesmo período, o colunista Maneco Muller inspirou-se em Winchell para criar a primeira coluna social moderna, com o pseudônimo de Jacinto de Thormes, em 1945 (SOUZA, 2009). O desenvolvimento das colunas sociais no Brasil ocorreu paralelo às mudanças no jornalismo no século $\mathrm{XX}$, resultando em colunas de notas contemporâneas, em que a política e a economia recebiam maior destaque comparativamente ao noticiário de outras editorias.

Manuel Antonio Bernardez Müller nasceu em 1923. Ficou mais conhecido pelos amigos como Maneco e, mais tarde, venerado pelo pseudônimo com que assinaria sua coluna social: Jacinto de Thormes, nome emprestado de um personagem do escritor Eça de Queiroz. Filho de diplomatas, Maneco era um grã-fino, como eram rotuladas as pessoas da alta sociedade sobre quem ele escreveria (SOUZA, 2007). Ajudou-lhe na vida jornalística a fluência em quatro línguas e o bom relacionamento com os ricos que sua ascendência lhe deixara. Iniciou sua carreira no jornal Folha Carioca.

Logo na primeira crônica, quase foi despedido porque se recusou a registrar passivamente o dia a dia da burguesia carioca (SOUZA, 2009). Escreveu notas com um estilo de crônica literária, adicionando comentários irônicos sobre seus "personagens", sem deslumbramento, como era comum. O que mais desagradou a alguns membros ali retratados é que o jovem colunista havia quebrado a tradicional "hierarquia" daquela época. Conforme Dines (1955), Maneco "ousara" retratar lado a lado figuras da burguesia carioca com artistas, políticos, e até pessoas "comuns", sem vínculo com as altas rodas.

Uma crise política retirou Maneco da Folha, mas, logo, foi contratado pelo Diário Carioca, jornal mais relevante que o primeiro e marcado por lutas políticas. O Diário era um periódico que, desde 1929, quando surgiu, jamais escondera sua vocação: ser um matutino eminentemente político e de oposição ao governo (SOUZA, 2007). Seu time de colaboradores era digno de provocar inveja em outros periódicos ${ }^{8}$. Maneco aceitou trabalhar no Diário com a condição de escrever com um pseudônimo: Jacinto de Thormes (NASSIF, 2006). Estava começando ali uma nova fase no jornalismo brasileiro. Conforme Ramalho (1998), antes de Maneco havia as "crônicas floridas" dos cronistas sociais. O termo colunista social surgiria depois, muito em parte por causa de Maneco, que também criou a expressão “colunável” (GONÇALVES, 1999). Com

\footnotetext{
${ }^{8}$ Alguns dos cronistas do Diário Carioca: Everardo Guilhon; Epitácio Timbaúba; Castelinho; Lúcio Rangel; Paulo Mendes Campos; Sérgio Porto; Vinícius de Moraes e Fernando Lobo.
} 
Maneco, a coluna social mudou: surgiu a crônica social com um estilo inconfundível, um misto de ironia, seriedade, esnobismo, fanfarronice e sarcasmo (RAMALHO, 1998).

Maneco trouxe para o Brasil o estilo das notas sincopadas. Ao apostar no colunismo social ao estilo norte-americano, Maneco inspirava-se em jornalistas que na América do Norte alcançavam enorme prestígio e poder.

Antes, [a coluna social] era assim porque a receita dela era essa. $\mathrm{Na}$ realidade, ela era ainda mais antiga e mais rebuscada. Havia um senhor chamado Gilberto Trompowski, que assinava G.B.A. Ele assinava verdadeiras crônicas, tipo "a senhorinha, fulana de tal, com um vestido esvoaçante...”, era por aí. Aí chegou o Maneco Muller, um sujeito muito culto, filho de embaixador, bem nascido, muito charmoso. E então o Maneco começou a fazer essa nova coluna que foi a origem de todas as outras ditas sociais (SOUZA, 2009, p. 72).

Enquanto o jornalismo se solidificava nos Estados Unidos, o cenário brasileiro estava muito atrás. O rádio e a imprensa detinham o monopólio da informação. Se nos Estados Unidos havia grandes tiragens de costa a costa, no Brasil os jornais de grande circulação eram vespertinos e poucos, concentrados no Rio de Janeiro e São Paulo. Os incipientes sistemas de comunicação, as deficiências dos correios e as precárias condições das redes e meios de transporte eram fatores que impediam a expansão rápida da comunicação por todo o território nacional (ABREU, 2003).

\section{Sobre a produção da coluna social}

A construção de uma coluna de notas passa por um jogo de interesses e poder entre colunistas e suas fontes. Apesar de a maioria dos colunistas brasileiros salientar a importância da apuração bem feita e a checagem dos fatos correta, as colunas são espaços mais livres, em que o responsável pode publicar rumores, insinuações, boatos, apenas para "medir a temperatura" de uma informação passada com exclusividade.

Com a ampliação de assuntos, a parte social desses espaços fica hoje restrita a pequenos registros e concorre com as assessorias de imprensa de gravadoras, editoras, empresas privadas e outros meios, ávidos por divulgar seus contratados. Políticos influentes divulgam com exclusividade aos colunistas informações sobre os bastidores do poder, que podem ser relevantes ao interesse público ou apenas servir ao jogo de interesses de lobbies estabelecidos nos principais postos do governo.

O jornalista Murilo César Ramos (2002) chega a definir como um novo gênero o que ele chama de jornalismo político das colunas sociais. Os colunistas, segundo ele,

\footnotetext{
${ }^{9}$ Anna Ramalho, colunista, em entrevista concedida a Souza, em julho de 2008 (2009, p. 72).
} 
estariam dedicando o espaço mais nobre das suas colunas à política: "São as notas que vêm em destaque, no alto das páginas, da esquerda para a direita, acompanhando, como manda a boa regra jornalística, o nosso jeito de ler" (RAMOS, 2002, p. 254).

Quando foram criadas, as colunas sociais, diferentemente das atuais, eram vistas como o lado informal do jornal, voltadas para o público feminino. Uma espécie de "descanso" concedido ao leitor das notícias sobre crimes, violência e mortes do chamado yellow journalism (no Brasil, imprensa marrom ou sensacionalista). Devido a essa característica, muitas delas se voltaram ao humor na formatação do texto. As notícias abordando os integrantes da burguesia eram levadas ao leitor algumas vezes de forma irônica, ressaltando o lado extravagante dos ricos e aos poucos dando maior importância às fofocas, ainda sem atingir seriamente a reputação dos personagens retratados.

Na década de 50, os colunistas sociais experimentaram o apogeu dentro dos jornais e entre o público leitor. Mesmo com a introdução na imprensa brasileira das modernas técnicas do lide, sublide, da objetividade, da imparcialidade e da pirâmide invertida, os colunistas continuaram com seu prestígio em alta. Nessa época, as colunas sociais, que se dedicavam ao mundo das festas e comemorações da burguesia brasileira, passaram por uma pequena alteração: os colunistas começam a investir sutilmente na política. Detalhes da vida privada de ricos e famosos começaram a ser intercaladas com o cotidiano dos titulares do Senado e da Câmara dos Deputados.

Foi durante a ditadura militar que Ibrahim Sued, com fortes relações com representantes da hierarquia militar, contribuiu para que, num período de censura prévia à imprensa, o público ficasse sabendo, lentamente, do que estava acontecendo nos bastidores do poder.

No início da década de 1950, eram raros os jornalistas chamados de colunista social, no Brasil. Mais difícil ainda era encontrar profissionais que atuassem no meio social, sem se fazer valer das "fofocas e de se deliciar com as festas da elite, sem nenhum senso crítico"10.

É nesse período que Ibrahim Sued transforma-se em uma marca do colunismo social brasileiro. Na coluna Zum-Zum, de sua autoria, publicada no jornal Vanguarda (RJ), o colunista apresentou um estilo próprio de noticiar o mundo e a elite carioca

\footnotetext{
${ }^{10}$ Grifo nosso.
} 
(TRAVANCAS, 2000). Ibrahim ${ }^{11}$ nasceu no Rio de Janeiro, a 23 de junho de 1924. Ganhou fama e notoriedade dentro e fora da profissão escrevendo suas colunas com personalidade, inventando termos e chavões, lançando personagens, criando modismos, elogiando e criticando pessoas famosas como bem entendia, sem temer as consequências. Tal comportamento colocou Ibrahim no topo da história do colunismo social brasileiro.

Ibraim se dizia inventor de um estilo jornalístico próprio com a criação de termos e expressões como: "Não convide para a mesma mesa fulano e beltrano", "Ademã que eu vou em frente" e "Cavalo não desce escada". A maior diferença de sua coluna, segundo ele próprio, era:

A minha coluna é informativa com comentários e, acima de tudo, criteriosa. Hoje qualquer "jacaré" ou "cobra d'água" que dá um jantar quer sair nas colunas. Na minha, não! Não é esnobismo, é critério. Se é uma coluna de sociedade, não vou botar "boca livre" em boate com pessoas mal vestidas, de tênis (SUED, 1993 apud MIGUEZ, 2014, p. 46).

\section{Avanço das notas: de 1960 a 1980}

Na linha do tempo, entramos na década de 1960, quando a coluna social se altera em decorrência da ditadura militar, instituída no Brasil a partir de 1964, com censura ao conteúdo dos jornais. Nesse período, avança a conscientização política dos trabalhadores. O mundanismo e a frivolidade, características marcantes das antigas colunas sociais, apesar de continuarem presentes nos espaços dos colunistas, tiveram seu espaço reduzido.

"A riqueza, o luxo e a ostentação - agora vistos por muitos como sinal de mau gosto - não frequentariam mais as colunas com a desenvoltura de antes" (ZOBARAN; CÂMARA, 1994, p. 103). Colunistas sociais, durante os anos 1970, no auge da repressão política, tiveram então de se reinventar para manter os espaços jornalísticos. Esse processo seria concomitante à modernização da imprensa e o aumento da tiragem dos jornais para além de seus estados de origem.

Com a nova realidade política, social e econômica, as colunas deixaram de ser locais e sociais. Ampliou-se a quantidade de assuntos abordados. O lado mais ameno e informal das colunas acabou sendo vantajoso. Elas eram vistas pelas autoridades militares e de seu governo como a seção de futilidades dos jornais. Assim, seus textos

\footnotetext{
${ }^{11}$ Neste artigo iremos nos referir aos colunistas da forma como eles ficaram conhecidos e não na forma da ABNT (último sobrenome do autor) no que se refere à citação dos colunistas.
} 
não eram vigiados pelos censores com o mesmo rigor das notícias políticas e econômicas.

Foi esta relativa liberdade durante os anos de chumbo que permitiu a alguns colunistas trânsito livre não só dentro dos grandes salões de festas, mas também aos bastidores do regime militar. Pouco a pouco as colunas receberiam informações sobre esse meio: notas que não teriam espaço nos primeiros cadernos, misturadas - ainda que muitas vezes de maneira cifrada - às notícias da alta sociedade, com informações preciosas sobre os bastidores da política (SOUZA, 2009, p. 45).

Nesse período, outra figura que marcou época no colunismo social foi Sérgio Porto. Na década de 1960, passou a parodiar Maneco e sua famosa lista das "dez mais elegantes". O cronista, que se apresentava com o pseudônimo Stanislaw Ponte Preta, criou as "Certinhas do Lalau", ou "as dez mais bem despidas", em contraste com o slogan "as dez mais bem vestidas" (SOUZA, 2009).

Durante a ditadura militar, o maior concorrente de $O$ Globo era o Jornal do Brasil, onde também fez história o colunista social Zózimo Barrozo do Amaral, ou simplesmente Zózimo, contratado em 1968 por Alberto Dines, editor do JB. Zózimo destacou-se por escrever bem e com estilo refinado e irônico, quando não, mordaz. Sua coluna misturava jornalismo de temática tradicional com informações políticas (SODRÉ; PAIVA, 2004, p. 28). Ele diversificou o colunismo. Além das notícias da sociedade, Zózimo falava sobre política, economia, esportes, literatura, música, teatro, artes plásticas, dança, comportamento e moda.

Entre 1970 e 1980, os colunistas não estavam preocupados apenas em "alimentar o supérfluo" e a levar em detalhes para o leitor o mundo de ostentação da alta sociedade. Além dos assuntos cada vez mais variados, na linguagem o estilo também mudava. Ao se transferir para $O$ Globo, em 1993, Zózimo apontava a mudança: "Eu tinha um quê de pretensão, abusava de galicismos do tipo enfant gaté e tour de force. Estou me policiando. Agora uso com freqüência curtir, transar" (BRASIL, 2006). Diminuiu o espaço para a sociedade e aumentou o estilo com humor e a tirada espirituosa.

\section{Década de 1990 e início do século XXI}

Na década de 1990, os jornalistas passaram a produzir textos menores com títulos sintéticos e muito uso da imagem. Proliferaram as colunas de notas curtas (ABREU, 2002). Segundo Gonçalves (1999, p. 39), “jamais o colunismo brasileiro 
esteve tão entulhado de exibicionismos e bisbilhotices do que nos anos 90". Conforme os estudos de Abreu, o motivo dessa mudança pode estar ligado a uma reação tardia da velha aristocracia burguesa, que, defendendo valores tidos por imóveis, ainda se sente capaz de tutelar, no sentido moral e pedagógico do termo, a conduta das novas elites (ABREU, 2002)

Nos jornais diários das capitais dos Estados do Brasil, os espaços ocupados pelos colunistas sociais no final do século XX e início de XXI não têm mais nada a ver com aqueles que consagraram Jacinto de Thormes, Ibrahim Sued ou Zózimo Barroso do Amaral. Em suas épocas,

as colunas recendiam puro glamour e desprezo pelo populacho e até pela classe média. Eles não escondiam sua adesão ao ideário aristocrático. Muitos compartilhavam intimidades com os colunáveis, confundindo-se com seus objetos de reportagem. Tomavam partido. Defendiam com unhas e dentes o direito da elite ser um espetáculo em si mesmo. E, sobretudo, tinham um enorme e variado poder. Aliás, nutriam uma consciência profunda de sua capacidade de influenciar diferentes meios sociais (GONÇALVES, 1999, p. 37-38).

O colunismo da década de 1990 é menos personalizado. Os colunistas não são, eles próprios, jornalistas importantes. As colunas continuam sendo "máquinas de bisbilhotice, estabelecendo conexões inesperadas, desvendando segredos e manipulando o afã coscuvilheiro dos leitores" (GONÇALVES, 1999, p. 38). O estilo mordaz, o suspense, a crítica, a ironia, o deboche, quase desapareceram (GONÇALVES, 1999).

\section{A coluna social no interior do Rio Grande do Sul}

Grande parte do segmento da imprensa conhecido por jornais interioranos ainda está por ser descoberto pelos pesquisadores gaúchos. Tentando preencher parte da lacuna existente quanto à compreensão e prática do jornalismo gaúcho, composto por mais de 400 jornais no Estado, vimos estudando a imprensa interiorana desde 1995.

Para o projeto de pesquisa que coordenamos desde 2014, em continuidade ao conhecimento existente sobre o jornalismo gaúcho, estabelecemos um corpus de pesquisa composto por 34 jornais interioranos distribuídos geograficamente pelo mesmo número de regiões do Estado ${ }^{12}$, com diferentes periodicidades, impressos e/ou on-line. Para o estudo da coluna social no século $\mathrm{XXI}^{13}$, analisamos seis jornais por um período

\footnotetext{
${ }^{12}$ As 34 regiões fazem parte de uma divisão feita pelo Instituto Brasileiro de Geografia e Estatística (IBGE).

${ }^{13} \mathrm{O}$ corpus de pesquisa do projeto que objetiva analisar e descrever a prática jornalística no interior do Rio Grande do Sul é composto por 34 jornais, que abrangem todas as regiões e microrregiões do Estado.
} 
de três meses, intercalados: janeiro, maio e outubro de 2015, sendo revisitados em março de 2017. O corpus foi composto pelos seguintes jornais: A Platéia, de Santana do Livramento; A Razão, de Santa Maria ${ }^{14}$; Correio Vacariense, de Vacaria; Diário da Manhã, de Passo Fundo; Jornal do Povo, de Cachoeira do Sul, e Panorama, de Taquara.

A história da coluna social no Rio Grande do Sul ao longo do século 20 baseouse em pesquisa bibliográfica, análise de conteúdo e entrevistas com seis editores e seis colunistas, preservando-se a identidade, a pedido dos próprios entrevistados. Os itens observados foram: autoria, estilo, perfil das fontes, origem das informações e presença de fotografias. Em relação à publicação das colunas sociais em portais eletrônicos dos jornais, acrescentamos as categorias texto multimídia (texto, imagem e som), interatividade (possibilidade do leitor comentar o noticiário, compartilhar e enviar matérias por $e$-mail) e periodicidade da atualização.

\section{Origem no Rio Grande do Sul}

No Rio Grande do Sul, o colunismo social apareceu na imprensa na década de 1950, com características copiadas de Maneco Müller, em um misto de ironia, sarcasmo, esnobismo e seriedade. Foi também dele que os colunistas gaúchos copiaram a expressão "colunáveis" e a divulgação do "Baile de Debutantes" e da "Lista das 10 mais elegantes", bem como dos "10 mais elegantes" (DORNELLES, 2004).

Antes da década de 50, os jornais traziam um espaço (pequeno), sob a denominação "Sociais", contendo notas de alguns eventos da elite local. Até 1959 poucas fotografias acompanhavam os textos dos colunáveis. A maioria dos cronistas sociais gaúchos daquela época, estendendo-se até o decênio de 80, era formada por mulheres, integrantes da elite, sobre a qual escreviam.

As colunas gaúchas de cidades do interior sempre mantiveram um estilo respeitoso, sério, elogioso, poético (dependendo do colunista) e, quase sempre, destacando as mesmas pessoas (DORNELLES, 2004). Foi frequente a localização de bordões criados pelas(os) colunistas(os) do interior, a exemplo do que faziam Maneco e Ibrahim.

As colunas sociais podem se caracterizar como reflexos identificativos da chamada "elite". No Rio Grande do Sul elas tiveram início em 1956, com a coluna

Por impossibilidade de espaço, destacamos de forma genérica as características identificadas nos jornais analisados, deixando os detalhes para outra produção científica.

${ }^{14}$ Lamentavelmente, em 25 de fevereiro de 2017, o jornal A Razão, fundado em 1934, encerrou suas atividades. 
Flash Social, do jornal Rio Grande. Conforme Pelissari (2012), essa foi a primeira coluna social a ser publicada no Estado.

O jornal Rio Grande foi fundado em 1913, tendo sido um dos jornais mais longevos da cidade de Rio Grande. A coluna Flash Social foi a primeira seção com o modelo do Rio de Janeiro. Antes disso, as notícias sociais eram dadas por meio de pequenas notas soltas ao longo dos jornais, a exemplo do que ocorria nos periódicos de outros municípios. Não havia ainda uma caracterização de coluna, responsável pela reunião de notas sob a tutela de um cronista. A coluna tratava, ainda, sobre os costumes, as regras e a moral próprios da época e do grupo social em questão.

No artigo intitulado Escavando o chão da futilidade: colunas sociais, fontes para o estudo de elites locais, Gonçalves (1999) descreve o ambiente do colunismo do interior, no final do século XX, que se ajusta perfeitamente ao Rio Grande do Sul:

Parte considerável dos colunáveis das pequenas cidades é meramente ocasional. Aqueles indivíduos formam segmentos das elites ad hoc, coadjuvantes, se exibindo para si e seu grupo imediato de referência. Suas fotos e/ou nomes aparecem para marcar episódios pessoais, como casamentos, aniversários, formaturas, homenagens, comparecimento a uma festa e coisas assim. Extraem um imenso prazer disso, mas nem sempre com arrogância ou empáfia. No interior, o deslumbramento e os elogios superlativos dão o tom absoluto das colunas sociais. Há pouca maledicência e não é comum o incentivo ao conflito entre grupos, famílias ou indivíduos notáveis. (GONÇALVES, 1999, p. 42).

Na primeira década do atual século, já na internet, os jornais estudados não apresentaram mudança significativa em sua estrutura, comparativamente à estrutura do século XX. Pelo contrário, deixaram de explorar o espaço ilimitado para divulgação de vídeos e de imagens e atualização diária do noticiário.

A Platéia, de Livramento, com circulação diária, oferece uma coluna social com frases breves e curtas, objetivas, com poucos adjetivos, no formato de notas, dando destaque aos principais eventos sociais da cidade: formaturas, aniversário de 15 anos, casamentos, nascimentos, notoriedades, atletas e artistas. As mesmas características foram observadas no jornal A Razão, de Santa Maria, também de circulação diária, e no Diário da Manhã, de Passo Fundo. Os três jornais representam, respectivamente, as regiões da Fronteira-Oeste, Centro e Noroeste.

A coluna social do jornal $O$ Correio Vacariense, um semanário, da região Campos de Cima da Serra, inclui notas sobre donos de comércios e instituições públicas 
e privadas, além de notícias sobre eventos de várias naturezas. Sua atualização on-line é semanal, acompanhando a distribuição do jornal impresso. O jornal Panorama, de Taquara, semanal, da região Paranhana, não tem colunista social, mas os jornalistas da redação escrevem sobre os eventos na cidade. O noticiário não apresenta nenhuma especificidade em relação ao jornalismo informativo de notas.

O Jornal do Povo, de Cachoeira do Sul, diário, da região Jacuí-Centro, apresenta as mesmas características já citadas, destacando-se, entretanto, o fato de o diário ter quatro colunistas, cada um responsável por uma cidade vizinha a Cachoeira do Sul. O periódico apresenta-se com uma proposta de cobertura regional dos acontecimentos.

A partir de entrevistas com colunistas sociais e editores, verificamos que vários colunistas complementam suas rendas - pessoais e empresariais, já que a maioria também atua como promotora de eventos - cobrando um cachê de certas pessoas que aparecem em seus espaços. Com frequência tudo depende "da cara do freguês" (conforme palavras dos próprios cronistas), do grau de intimidade mantida ou desejada, das vantagens que o colunista espera obter abrindo espaço para tal ou qual personagem, dos lucros diretos ou indiretos que podem ser auferidos. Alguns jornais, que produzem as colunas sem colunistas, têm tabela de preços para publicação de notas e fotos; outros, não.

Nas cidades do interior do Estado, pelas dificuldades econômicas dos jornais para aquisição de impressoras de qualidade, as fotografias só foram se instalar de fato nas colunas a partir da década de 1990. Mesmo assim, até hoje, especialmente em jornais semanários, encontramos colunas com predominância dos textos e poucas ou nenhuma fotografia, confundindo-se com crônicas.

Parzianello (2011), em pesquisa realizada entre 2009 e 2011, identificou, a partir de entrevistas com os produtores e leitores dos jornais da região do Pampa e Meso-Sul do Rio Grande do Sul e de análise dos exemplares, que a política de relação dos jornais com seus leitores requer ações estratégicas mais efetivas para alcançar eficiência e eficácia na sobrevida dos periódicos. A linguagem dos veículos reforça cada vez mais a cultura do apego ao passado e à descrença no futuro. $\mathrm{O}$ visual dos jornais impressos mostra uma acomodação de modelos, sem quase nenhum apelo renovador.

As regiões estudadas são reconhecidas e se reconhecem como inferiores a outras com características muito semelhantes, e em razão disso se anunciam como atrasadas e impedidas de promoverem qualidade (PARZIANELLO, 2011). Essas mesmas marcas 
também foram verificadas nas colunas sociais produzidas ainda hoje. Acreditamos que jornais do interior de outras regiões do Brasil apresentem características bastante semelhantes às que encontramos no Rio Grande do Sul. Em um novo texto, detalharemos a passagem da coluna social do impresso para o digital, apontando características que se perderam e outras que surgiram. Arriscamos afirmar que, caso não ocorra uma mudança nos padrões de produção da coluna social, ela está fadada a desaparecer dos jornais digitais de todo o Estado, podendo ocorrer o mesmo em jornais de outros estados com características semelhantes.

\section{REFERÊNCIA BIBLIOGRÁFICA}

ABREU, João Batista de. Imprensa x censura: a luta armada das palavras. Entrevista ao portal Observatório da Imprensa, out. 2002. Disponível em:

<http://observatoriodaimprensa.com.br>. Acesso em: 14 abr. 2015 e 05 set. 2017.

BRASIL, Ubiratan. A rotina inovadora do colunista Zózimo. Edição 368, 14 fev.

2006. Disponível em: <http://observatoriodaimprensa.com.br/feitos-

desfeitas/o_estado_de_s_paulo_2/>. Acesso em: 18 abr. 2015 e 05 set. 2017.

BROCA, Brito. A vida literária no Brasil 1900. São Paulo: José Olympio, 2004.

DINES, Alberto. Gatos e damas de preto: cronistas disputam a preferência do café society. In: Revista Visão, 18 mar. 1955.

FERREIRA, Alexandre Leonardo de Alvarenga. Coluna social: elementos utilizados pelo colunismo social que remetem ao processo de projeção e identificação do público, caracterizado por Edgar Morin. 2006. 40 f. Monografia (Graduação em Comunicação Social) - Centro Universitário de Belo Horizonte, Belo Horizonte, 2006.

DORNELLES, Beatriz. Jornalismo "comunitário" em cidades do interior. Porto Alegre: Sagra Luzzatto, 2004.

GONÇALVES, José Henrique Rollo. Escavando o chão da futilidade: colunas sociais, fontes para o estudo de elites locais. Revista de História Regional, v. 4, n. 2, inverno 1999, p. 35-59. Disponível em: <http://www.revistas2.uepg.br/index.php/rhr/article/view/2082>. Acesso em: 23 mar. 2015 e 25 ago. 2017.

KOVÁCS, Anamaria. Coluna social: linguagem e montagem. Comum. Rio de Janeiro, p. 37-90, v. 5, 1979. Disponível em: <https://www.facha.edu.br/pdf/Comum05.pdf>. Acesso em: 18 abr. 2015. 
MIGUEZ, Maria Cristina Porto. Colunismo social: a informação de primeira (e em constante mudança). Revista Augustus. Rio de Janeiro, v. 19, n. 37, p. 44-54, jan./jun. 2014.

Disponível

em:

<http://apl.unisuam.edu.br/revistas/index.php/revistaaugustus/article/view/19811896.2014v19n37p44>.

NASSIF, Luís. O cronista do Rio. Disponível em: <www.lainsignia.org/2006>. Acesso em: 15 abr. 2017.

PARZIANELLO, Geder. A retórica nos jornais impressos e os desafios ao jornalismo contemporâneo. Rio de Janeiro: Publit, 2011.

PELISSARI, Marina Krüger. A "mais fina sociedade riograndina" e suas representações: a vida social da elite de Rio Grande-RS (1956 a 1960). 2012. 202 f. Dissertação (Programa de Pós-Graduação em História) - Instituto de Filosofia e Ciências Humanas, Universidade Federal do Rio Grande do Sul, Porto Alegre, 2012. Disponível em: <http://www.lume.ufrgs.br/handle/10183/69833>. Acesso em: 18 abr. 2015.

RAMALHO, Anna Maria. Coluna social. In: Lições de jornalismo 1. Rio de Janeiro: Editora Faculdade da Cidade, 1998.

RAMOS, Murilo César. Intrigas da corte: jornalismo político nas colunas sociais. In: MOTTA, Luiz Gonzaga (Org.). Imprensa no poder. Brasília: Editora UNB, 2002, p. 247-260.

SODRÉ, Muniz; PAIVA, Raquel. Cidade dos artistas: cartografia da televisão e da fama no Rio de Janeiro. Rio de Janeiro: Mauad, 2004.

SOUZA, Rogério Martins de. Colunas sociais e ditadura militar: entre o mundo fictício da alta sociedade e os bastidores da política e economia. ENCONTRO NACIONAL DE PESQUISADORES EM JORNALISMO (SBPJOR), 5., Aracaju, 2007. Universidade Federal de Sergipe, 15-17 nov. 2007. Disponível em: $<$ https://www.yumpu.com/pt/document/view/12950295/colunas-sociais-e-ditaduramilitar-entre-o-mundo-ficticio-sbpjor>. Acesso em: 04 abr. 2015 e 17 ago. 2017.

Dos canapés à política: a reinvenção permanente do colunismo como gênero jornalístico. 2009. 232 f. Tese (Doutorado em Comunicação) - Escola de Comunicação (ECO), Universidade Federal do Rio de Janeiro, Rio de Janeiro, 2009.

SUED, Isabel (Org.). Em sociedade tudo se sabe. Rio de Janeiro: Rocco, 2001.

TRAVANCAS, Isabel. A coluna de Ibrahim Sued - um gênero jornalístico. Biblioteca On-line de Ciências da Comunicação-BOCC. Disponível

em: <http://www.bocc.ubi.pt/pag/travancas-isabel-coluna-ibrahim-sued.pdf>. Acesso 
em: 20 ago. 2017 e 23 nov. 2017.

ZOBARAN, Sergio; CÂMARA, Leopoldo. A segunda imprensa - guia para divulgadores e divulgados. Rio de Janeiro: Rocco, 1994.

Submetido em 04.04.2016

Aceito em 29.10.2017 